\title{
Modeling and Simulation of a Wind Turbine Driven Induction Generator Using Bond Graph
}

\author{
A. Ramdane *, A. Lachouri ", M. Krikeb * \\ *Team Leader in Automatic Laboratory, Electrical Engineering Department, Faculty of Technology, \\ University of 20 August 1955, Skikda. 21000, Algeria, ID, 83844-1133, USA., \\ E-mail: Adlene_soft2005@yahoo.fr, alachouri@yahoo.fr, krikeb@yahoo.fr
}

\begin{abstract}
This paper deals with the modelling and simulation of wind turbine driven by induction generator. Usually in mechatronic systems, several types of energy are involved. By its nature of a power conserving description of a system, the Bond-Graph method is especially practical when several physical domains have to be modeled within a system simultaneously. This is certainly the case in wind turbine systems where mechanical and electrical systems in several combinations are present. This work presents an implementation of the wind turbine model in bond graph approach. Simulation results are carried out by means of simulation in 20-sim software environment.
\end{abstract}

Keywords - wind turbine, modelling, bond graph, induction generator.

\section{INTRODUCTION}

Energy consumption has increased considerably in recent years with the technology evolution. This has increased the demand for fossil fuels and has made firstly, electrical energy more expensive and secondly, the fossil fuels have a several disasters on the environment protection by the emissions of greenhouse gases and undesired particles into the atmosphere. Because of such reasons, it is necessary to focus on other forms of energy production to meet the growing needs of today's world. Furthermore, the wind energy, being one as an efficient source of alternative and cleanest sources of electricity, has emerged as one of the most preferred sources for electricity generation.

The wind energy is the kinetic energy of the flowing air mass per unit time. Therefore, when performing wind power integrated network planning or analysis of the operation, the engineers have put a lot of effort in modelling the wind rather than focusing on the problem itself. Thus, a wind model compatible with the analytical tools of commercial power system is in imminent need.

In Electromechanical Engineering, the global analysis of systems is difficult because of their heterogeneity and their multi-domains nature. Nevertheless, this system approach is essential because it underlines couplings between elements of different physical fields. To facilitate this analysis, the unified formalism Bond Graph is used. This modelling method illustrates the energetic transfers in the system. Moreover, this methodology offers interesting solutions in terms of system analysis.

Much research has been done on the modelling and control of wind turbines [2], [4], [6] and [7]. Most of this research has been done using simple wind mechanical and aerodynamic models that overlook a number of important features. Research on wind turbines based on more sophisticated mechanical and aerodynamic models was made only with relatively simple models of electric generator, its controllers, and model of the power system. This is because most researchers who have studied the wind power, they are focusing on aspects either electrical or mechanical part, without paying attention to the operation of the complete electromechanical system. There are many types of WT models, ranging from single mass, one state model to multiple mass models. In a simulation point of view, it is desirable that the model is as simple as possible and can capture as much of the dynamics that appear in reality.

In this context, our study is interested in the wind turbine system. This document is based on modelling and simulation method with Bond Graph (BG) applied to the wind turbine driven by generator induction. This method becomes a powerful tool when the complex interaction of subsystems of different types should be evaluated. The paper is organised as follows: The section 2 gives a brief introduction on bond graph methodology then, on finds in section 3 a modelling of different parts of wind turbine system and their 
bond graph in 20-sim software is presented. In section 4 is illustrated the simulation results and theirs discuss. A conclusion is given at the end of this paper.

\section{BOND GRAPH}

\section{A. Bond Graph methodology}

The methodology of the bond graph modelling is based on the characterization of power exchange phenomena within a system. The idea of the bond graph modelling is the representation of dissipated power as the product flow and effort to bind the various junctions to reproduce the system. The bond graph is a powerful tool in modelling systems; especially in cases where subsystems of different physical character (mechanical, electrical, thermal, hydraulic ...) are interact. The exchange of energy between the subsystems of a more complex system in bond graph modelling is of an essential significance. Bond graph is therefore a directed graph whose nodes represent subsystems and arrows - the transfer of energy between the subsystems.

\section{B. Bond Graph Elements}

In BG modelling, there are a total of nine different elements. We will first present the basic elements of $B G$ and introduce the causality assignments.

Source element: there are two type of 1-ports source: the effort source and the flow source. In each case, an effort or flow is assumed to be maintained constant independent of the power supplied; the constitutive relation and causality is showing in Fig.1.

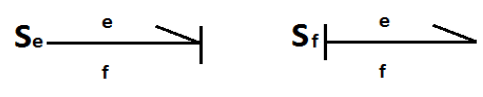

Fig .1. Sources elements

Resistive element: is an element in which the effort and flow variables at the single port are related by a static function Fig2.

Inertia element: the inertia port corresponds to the electrical inductors, the momentum $p$ is related the flow $f$. There are two choices for the causality assignment for the I-element Fig2.

Compliance element: is an element that relates effort e and displacement q. the power flows into the port and a sign convention similar to that used for the resistor is adopted Fig.2.
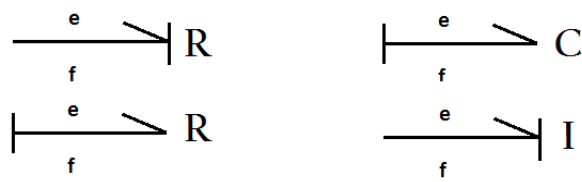

Fig .2. Resistance, Inertia and compliance elements

Transformer and gyrator: the transformer and gyrator can work in two ways; transformer transforms a flow to another flow or an effort to another effort. The gyrator transforms a flow into an effort or transforms the effort into a flow.
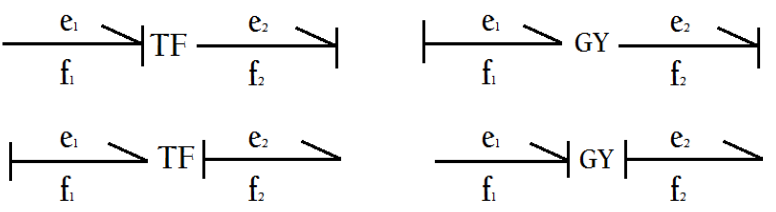

Fig .3. Transformer and Gyrator elements

Junctions: there are two different types of junctions that connect the different parts in BG, the 0 -junction and 1 -junction. Junctions are power conserving at each instant and the power transport of all bonds add up to zero at all times. The junction elements represent the two types of connections, which, in electrical terms, are called the series, and parallel connections

\section{MODEL DESCRIPTION}

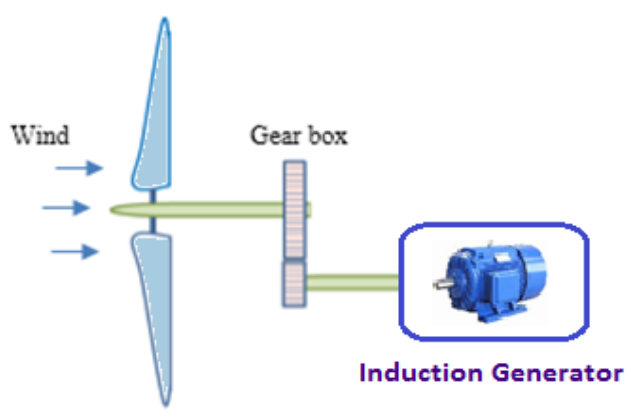

Fig .4. Wind turbine model description

In this section, the dynamic simulation model is described for the proposed wind turbine energy conversion. The block diagram of the integrated overall system is shown in Fig.4. Afterwards, each sub-model of the wind turbine is presented and 
combined to obtain a complete model of the wind turbine.

The all parts of system modelling in 20-sim software is showing in Fig.5.

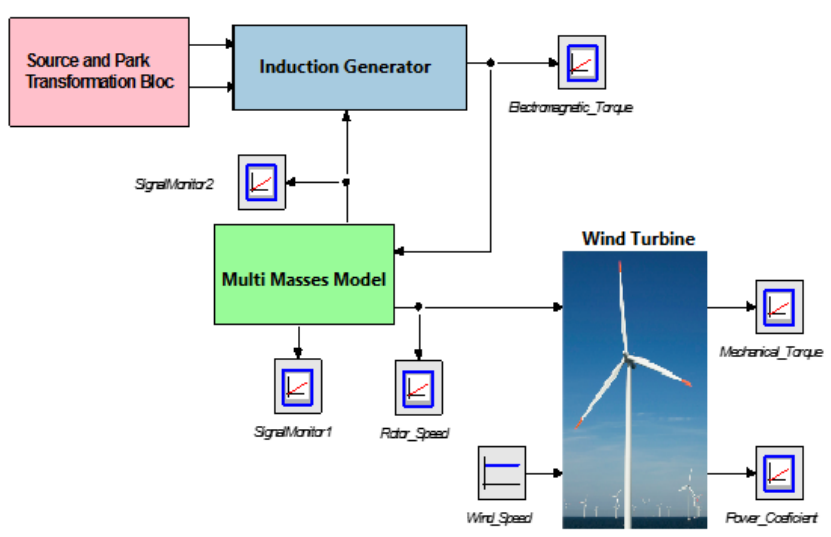

Fig .5. System Parts modelling in 20-sim software

\section{A. Aerodynamic Model}

Wind turbine electrical generation systems power comes from the kinetic energy of the wind. Thus, it can be expressed as the kinetic power available in the stream of air multiplied by a $\mathrm{Cp}$ factor called power coefficient or Betz's factor. The Cp Mainly depends on the relation between the average speed of the air across the area covered by the wind wheel and its angular speed and geometric characteristics of the turbine. The power extracted by the wind turbine has the following expressions [2]:.

$P_{w}=\frac{1}{2} \cdot \rho \cdot A \cdot C_{p} \cdot V_{W}{ }^{3}$

$A=\pi \cdot R^{3}$

Where $P_{w}$ is the air stream kinetic power, $\rho$ the air density assumed to be constant, $A$ is the surface covered by the wind wheel and $V_{W}$ the average wind speed. The power that wind turbine can catch from wind is:

$T_{W}=\frac{P_{w}}{\Omega}$

There have been different approaches to model the power coefficient ranging from considering it to be constant for steady state and small signal response simulations to using lookup tables with measured data. Another common approach is to use an analytic expression [2]:
$C_{p}=0.22\left(\frac{116}{\lambda^{\prime}}-0.4 \beta-5\right) e^{\frac{-12.5}{\lambda^{\prime}}}$

With:

$$
\frac{1}{\lambda^{\prime}}=\frac{1}{\lambda+0.08 \beta}-\frac{0.035}{\beta^{3}+1}
$$

Where $\lambda$ is so called tip-speed ration and it is defined

as $\lambda=\frac{\omega R}{V_{w}}$

and $\beta$ is the pitch angle.

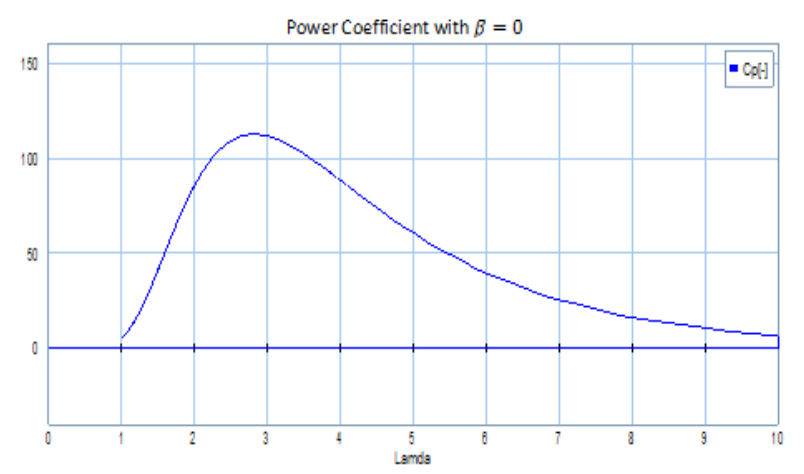

Fig .6 Power Coefficient of wind turbine

In general the $C_{p}$ coefficient is represented by the Graph which depends on the tip-speed ratio $\lambda$ and the pitch angle $\beta$.

The bond graph of aero-dynamical part of wind turbine model implemented in 20-sim software from [4] is show in Fig.4.

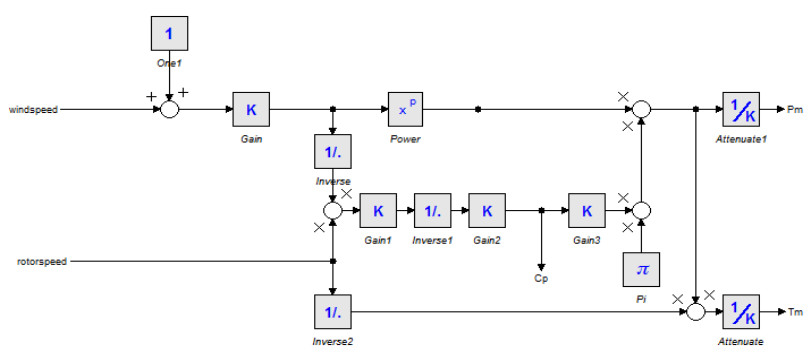

Fig .7 The bloc diagram Model of Aero-dynamical part of wind turbine model in 20-sim Software

\section{B. Mechanical Part}

The mechanical part of the wind turbine system includes all the mechanical elements of Systems (blades, lock rotor, shafts, Speed Multiplier (gear box) 
... etc.).This multiplier is modelled mathematically in

[3] for the following equations:

$$
C_{r}=\frac{T_{m}}{G}
$$

$$
\mathbf{\Omega}_{\text {turbine }}=\frac{\Omega_{m e c}}{G}
$$

\section{G: The speed multiplier gain}

$J=\frac{J_{\text {turbine }}}{G^{2}}+J_{r}$

The fundamental equation of dynamics used to determine the evolution of the mechanical speed from the total mechanical torque $\left(\boldsymbol{C}_{\boldsymbol{m e c}}\right)$ applied to the rotor:

$J \frac{d \Omega_{m e c}}{d t}=C_{m e c}$

$J$ The total inertia appears on the generator rotor. The mechanical torque depends on the electromagnetic torque $\left(\boldsymbol{C}_{\boldsymbol{e}}\right)$ produced by the generator, the torque of viscous friction $\left(\boldsymbol{C}_{v i s}\right)$ and load torque $\left(\boldsymbol{C}_{\boldsymbol{r}}\right)$.

$C_{m e c}=C_{r}-C_{e m}-C_{v i s}$

The viscous torque is modelled by.

$$
C_{v i s}=f . \Omega_{m e c}
$$

$f$ : Is the viscous friction coefficient.

\section{Three Masses Model}

The equivalent model of a wind turbine drive train is presented in Fig 6. The masses correspond to a large mass of the wind turbine rotor, masses for the gearbox wheels and a mass for generator respectively.

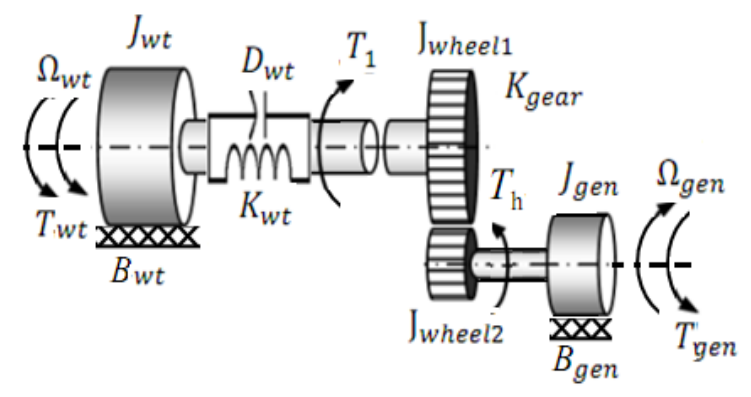

Fig 6. Three-mass model of a wind turbine drive train.
The inertia of the low-speed shaft also includes the inertia of the rotor, while the friction component includes bearing frictions. The dynamics of the lowspeed shaft is:

$T_{w t}-T_{1}-B_{w t} \Omega_{w t}=J_{w t} \frac{d \Omega_{w t}}{d t}$

Where:

$B_{w t}$ Is the viscous friction of the low-speed shaft $[\mathrm{Nm} /(\mathrm{rad} / \mathrm{s})]$,

$J_{w t}$ Is the moment of inertia of the low-speed shaft [Kgm2],

$T_{w t}$ is the torque acting on the low-speed shaft [Nm],

$\theta_{w t}$ Is the angle of the low-speed shaft [rad],

The inertia of the high-speed shaft also includes the inertia of the gearbox and the generator rotor. The friction coefficient covers bearing and gear frictions. The dynamics of the high-speed shaft is:

$T_{h}-T_{g e n}-B_{g e n} \Omega_{g e n}=J_{g e n} \frac{d \Omega_{g e n}}{d t}$

Where:

$B_{g e n}:$ The viscous friction of the high-speed shaft [Nm/(rad/s)];

$J_{\text {gen }}:$ The inertia moment of the high-speed shaft $\left[\mathrm{Kgm}^{2}\right]$;

$T_{\text {gen }}:$ The generator torque $[\mathrm{Nm}]$;

$T_{h} \quad$ : The torque acting on the high-speed shaft [Nm];

$\theta_{\text {gen }}:$ The angle of the high-speed shaft [rad];

The remaining part of the gearbox modeling is to apply a gear ratio, as defined below.

$T_{h}=\frac{T_{1}}{K_{\text {gear }}}$

$K_{\text {gear }}$ is the drive train gear ratio.

The torsion of the drive train is modelled using a torsion spring and a friction coefficient model, described according to:

$T_{1}=K_{w t} \theta_{\Delta}+D_{w t} \dot{\theta}_{\Delta}$

$\boldsymbol{\theta}_{\Delta}=\boldsymbol{\theta}_{\boldsymbol{r}}-\frac{\boldsymbol{\theta}_{\text {gen }}}{\boldsymbol{K}_{\text {gear }}}$

Where:

$D_{w t}$ is the viscous friction of the low-speed shaft $[\mathrm{Nm} /(\mathrm{rad} / \mathrm{s})]$

$K_{w t}$ is the torsion stiffness of the drive train [Nm/rad]

$\theta_{\Delta}$ is the torsion angle of the drive train [rad]

$T_{1}(t)=K_{w t}\left(\theta_{r}-\frac{\theta_{g e n}}{K_{g e a r}}\right)+D_{w t}\left(\Omega_{w t}-\frac{\Omega_{g e n}}{K_{g e a r}}\right)$

After simplification and substituting equations obtains 


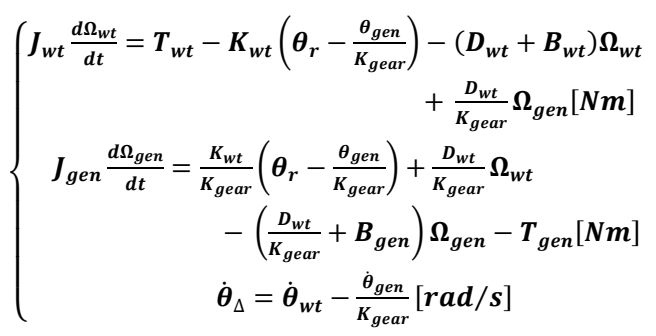

Three first order differential equations have been derived in this section in order to describe the behavior of the drive train. In the next section, the effect on the tower from the aerodynamic thrust is considered.

Bond graph bloc diagram model of three masses system is showing in Fig.8.

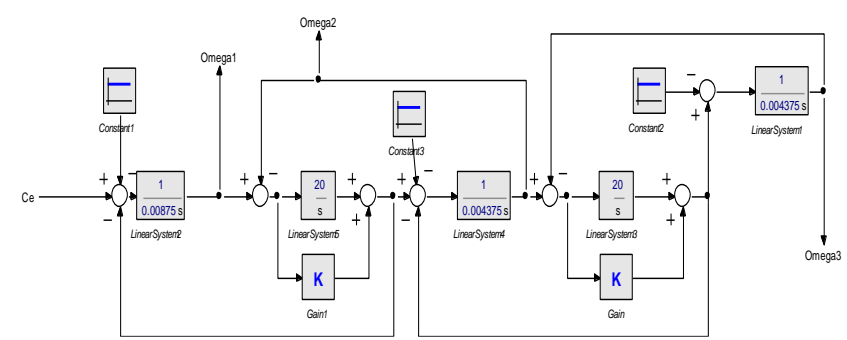

Fig 8. Multi masses system model

\section{Electrical Part}

The generator used for the wind system is an asynchronous squirrel-cage generator whose parameters are quoted in table1. The model of the asynchronous machine is deduced from the twophase machine by supposing that the variables are expressed in a reference frame $x-y$ turning at the speed of the electric field. The results obtained by simulation illustrate the behaviour of this generator and give the par values of operation.

The induction machine equations are [2]:

$$
\left\{\begin{array}{c}
U_{s x}=R_{s} I_{s x}+S \Psi_{S X}-\omega_{S} \cdot \Psi_{S Y} \\
U_{s y}=R_{s} I_{s y}+S \Psi_{S y}-\omega_{S} \cdot \Psi_{S x} \\
0=R_{r} I_{r x}+S \Psi_{r x}-\left(\omega_{S}-\omega_{r}\right) \Psi_{r y} \\
0=R_{r} I_{r y}+S \Psi_{r y}-\left(\omega_{S}-\omega_{r}\right) \Psi_{r x} \\
C e=P \cdot L_{s r}\left(I_{s y} \cdot I_{r x}-I_{s x} \cdot I_{r y}\right) \\
\Psi_{\mathrm{S}}=\mathrm{L}_{s} \cdot \mathrm{I}_{\mathrm{s}}+\mathrm{L}_{\mathrm{sr}} \cdot \mathrm{I}_{\mathrm{r}} \\
\Psi_{\mathrm{r}}=\mathrm{L}_{\mathrm{r}} \cdot \mathrm{I}_{\mathrm{r}}+\mathrm{L}_{\mathrm{sr}} \cdot \mathrm{I}_{\mathrm{s}}
\end{array}\right.
$$

This system can be presented as follows:

$$
\left\{\begin{aligned}
S \Psi_{s x} & =U_{s x}-R_{s} \cdot I_{s x}+\omega_{s} \cdot \Psi_{s y} \\
S \Psi_{s y} & =U_{s y}-R_{s} \cdot I_{s y}+\omega_{s} \cdot \Psi_{s x} \\
S \Psi_{r x} & =R_{r} \cdot I_{r x}+\left(\omega_{S}-\omega_{r}\right) \Psi_{r y} \\
S \Psi_{r y} & =R_{r} \cdot I_{r y}+\left(\omega_{S}-\omega_{r}\right) \Psi_{r x} \\
C e & =P \cdot L_{s r}\left(I_{s y} \cdot I_{r x}-I_{s x} \cdot I_{r y}\right) \\
I_{s} & =\frac{\mathrm{L}_{r} \cdot \Psi_{s}+\mathrm{L}_{s r} \cdot \Psi_{r}}{\mathrm{~L}_{s} \cdot \mathrm{L}_{r}-\mathrm{L}_{s r}{ }^{2}} \\
I_{r} & =\frac{\mathrm{L}_{s} \cdot \Psi_{\mathrm{r}}+\mathrm{L}_{s r} \cdot \Psi_{s}}{\mathrm{~L}_{s} \cdot \mathrm{L}_{r}-\mathrm{L}_{s r}{ }^{2}}
\end{aligned}\right.
$$

$U_{S X}, U_{s y}:$ The stator voltage Components expressed in $x-y$ reference.

$I_{S X}, I_{s y}$ : The stator current Components expressed in $\mathrm{x}-\mathrm{y}$ reference.

$R_{S}:$ Stator resistance;

$R_{r}:$ Rotor resistance;

$L_{S}:$ Stator Inductance;

$L_{r}:$ Rotor Induction;

$L_{S r}:$ Mutual inductance;

$P$ : Number of pole pairs;

$C_{e}$ : Electromechanical torque;

$\omega_{S}:$ Speed of the electric field;

$\omega_{r}$ : Electric rotor speed;

The bond graph of induction machine in 20-sim software using library developed in [5] is showing in Fig.9.

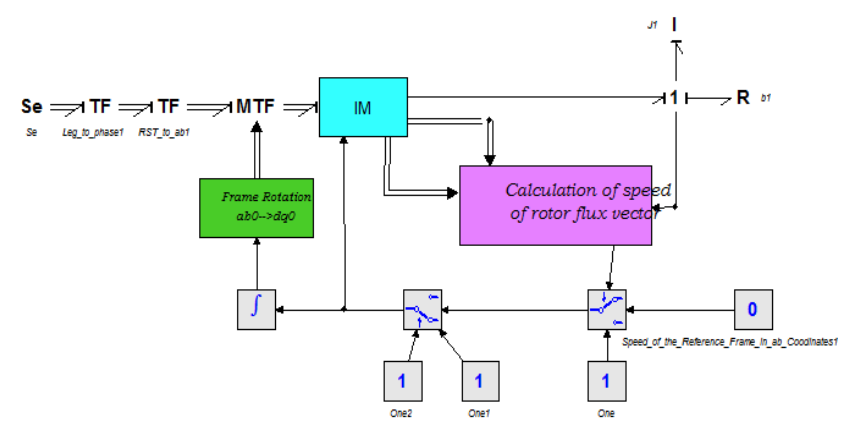

Fig 9. Induction Generator bond graph model

\section{SIMULATION RESULTS}

Simulation step is done on a specific bond graph software 20-sim, which is an object oriented hierarchical modelling software. It allows users to create models using bond graph, block-diagram and equation models. A list of numerical values of wind turbine system parameters used in this simulation is presented in Table-1. 
Table 1. Model Parameters

\begin{tabular}{|l|c|}
\hline Nominal Power & $\mathrm{Pn}=180 \mathrm{KW}$ \\
\hline Rotor Diameter & $\mathrm{D}=23.2 \mathrm{~m}$ \\
\hline Rotor Speed & 23.75 \\
\hline Multiplier Coefficient & 3 \\
\hline Number of Blades & $\rho=1 \mathrm{Kg} / \mathrm{m}^{3}$ \\
\hline Air Density & $\mathrm{J}_{\mathrm{T}}=102,8 \mathrm{Kgm}{ }^{2}$ \\
\hline Turbine Moment Inertia & $\mathrm{J}_{\mathrm{G}}=4,5 \mathrm{Kgm}$ \\
\hline Generator Moment Inertia & $\mathrm{K}_{12}=2700 \mathrm{Nm} / \mathrm{rad}$ \\
\hline Rigidity Coefficient & $\mathrm{B}_{12}=0.1 \mathrm{Nms} / \mathrm{rad}$ \\
\hline Damping Coefficient & $\mathrm{P}=3$ \\
\hline Number of Pairs & $\mathrm{Rs}=0.0092 \Omega$ \\
\hline Stator Resistance & $\mathrm{Rr}=0.0061 \Omega$ \\
\hline Rotor Resistance & $\mathrm{Lls}=186 \mu \mathrm{H}(\mathrm{Ls}=\mathrm{Lls}+\mathrm{Lm})$ \\
\hline Stator Mutual Inductance & $\mathrm{Llr}=427 \mu \mathrm{H}(\mathrm{Lr}=\mathrm{Llr}+\mathrm{Lm})$ \\
\hline Rotor Mutual Inductance & $\mathrm{Lm}=6.7 \mathrm{mH}(\mathrm{Lsr}=\mathrm{Lm})$ \\
\hline Magnetizing Inductance & \\
\hline
\end{tabular}

The Fig.5 shows all parts of system modelling implemented in 20-sim software. The Fig. 6 presents the Power Coefficient $C_{p}$ evolution function of tipspeed ration $(\lambda)$. Through this figure, we can easily see that the evolution of the $C_{p}$ retrieve its maximum at the $\lambda_{o p}=3$. The Fig. 7 illustrated a bond graph bloc diagram Model of Aero-dynamical part of wind turbine and Fig. 8 presents a Bond graph of Multi mass model under 20-sim software. The Fig.9 depicts Induction Generator bond graph model. The Fig.10 and Fig.11 show the mechanical power and torque curves respectively of the wind turbine. They occur the maximum point at the $\lambda_{o p}=3$. The Fig. 12 shows the power coefficient with blade pitch $\beta$ and its maximum value at $\lambda_{o p}=3$. With regard to the instantaneous torque (Fig.13), we can indicate the presence of oscillations in magnitude for a very short time at start up, and then these oscillations are cleared. Figures (Fig.14-16) show the curves velocities of multi-mass model. They have strong oscillations during the transient regime during $0.02 \mathrm{~s}$, and converse to its nominal speed at $157 \mathrm{rad} / \mathrm{s}$.

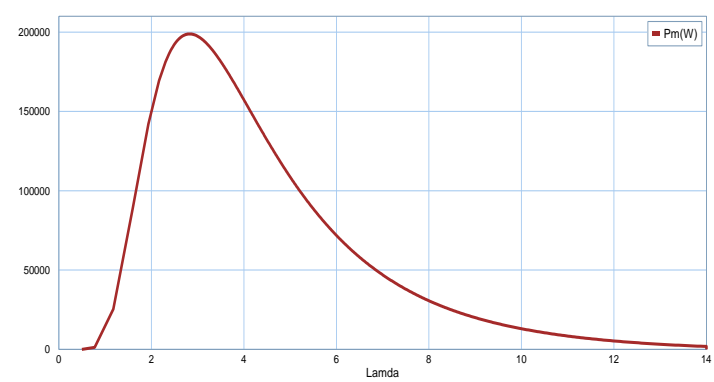

Fig 10. Mechanical Power in 20-sim software

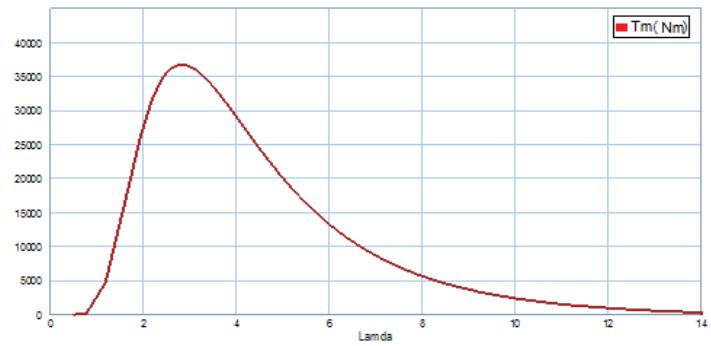

Fig 11. Mechanical Torque In 20-sim Software

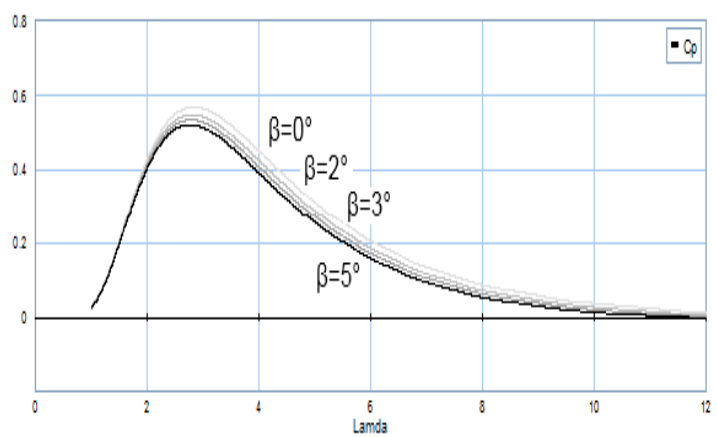

Fig 12. Power Coefficient

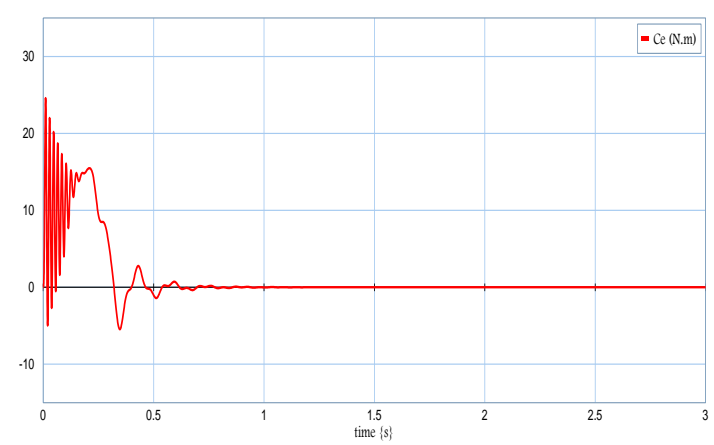

Fig 13. Torque characteristic

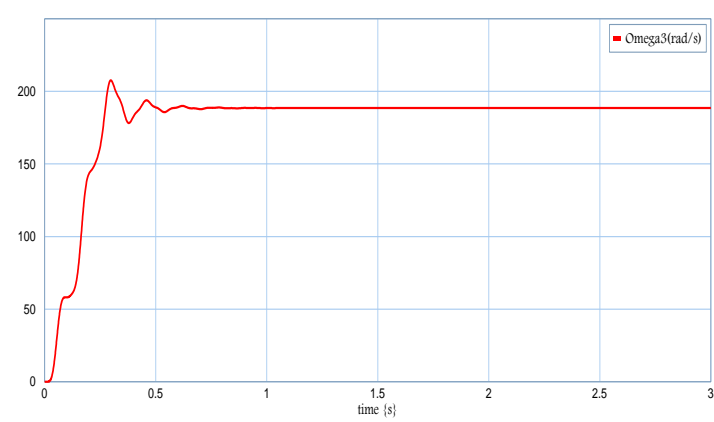

Fig 14. First mass Speed

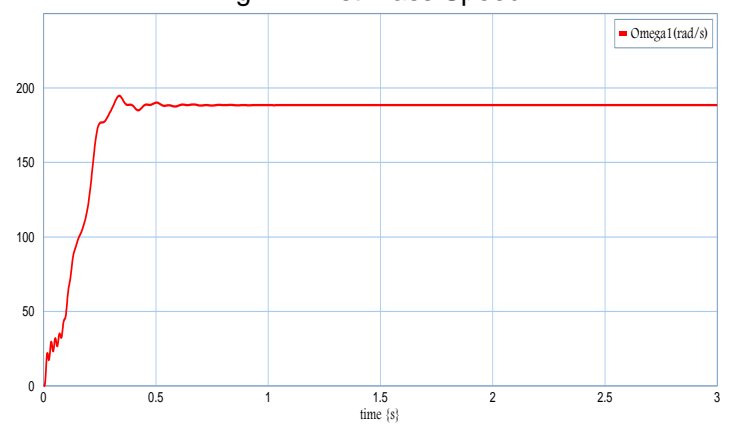

Fig 15. Second mass Speed 


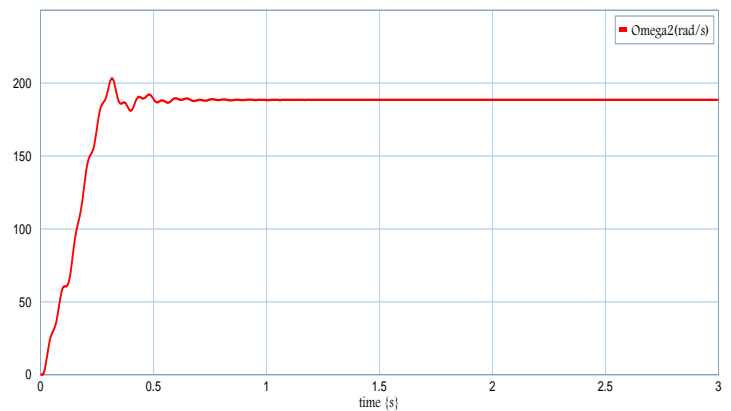

Fig 16. Third mass Speed

\section{CONCLUSION}

In this paper, a power conversion system was studied with a "system viewpoint methodology" by using a Bond Graph technique. However, the different fields of energy conversion, the nonlinearity and the different dynamics of the system involve the use of a global unified formalism for studying the global system. The software "20-sim" permit to implemented the bond graph system model's. The simulation results from this approach confirm one of the benefits of $B G$ as a generally usable approach to modelling mechatronic systems and offers interesting solutions in terms of system diagnosis and analysis.

\section{REFERENCES}

[1] A.Djeziri, R. Merzouki, B. Ould Bouamama, G. Dauphin-Tanguy. 'Bond Graph Model Based For Robust Fault Diagnosis' IEEE, 2007, 1-42440989-6/07.

[2] Sanae Rechka, GillesRoy, Sébastien Dennetiere et Jean Mahseredian,'Modélisation de systèmes électromécanique multi-masses à base de machines asynchrones, à l'aide des outils MATLAB et EMTP,avec Application aux éoliennes ,juillet 2004.

[3] F. Kendouli, K. Nabti, K. Abed et H. Benalla,' Modélisation, simulation et contrôle d'une turbine éolienne à vitesse variable basée sur la génératrice asynchrone à double alimentation ' Revue des Energies Renouvelables Vol. 14 №1 (2011) $109-120$.

[4] J.G. Slootweg, S.W.H.H Polinder and W.L. king, 'General Model for representing variable speed wind turbines in power systems dynamics simulations', IEEE Transaction on power system, Vol 18, No. 1, February 2003, pp. 144-151.

[5] Sergio Junco, Gonzalo Dieguez, Facundo Ramirez, ' une librairie 20-sin pour la simulation basée bond graphs de système de commande des machines électrique 'cifa_2008_T18-I-070338 .

[6] Lucian Mihet-Popa, Frede Blaabjerg, Ion Boldea,' Wind Turbine Generator Modeling and Simulation Where Rotational Speed is the Controlled Variable',IEEE Transactions On Industry Applications, Vol. 40, No. 1, January/February 2004.

[7] B. ChittiBabu , K.B. Mohanty,' Doubly-Fed Induction Generator for Variable Speed Wind Energy Conversion Systems- Modeling \& Simulation', International Journal of Computer and Electrical Engineering, Vol. 2, No. 1, February, $2010,1793-8163$.

[8] Tore Bakka and Hamid Reza Karimi,' Wind Turbine Modeling Using The Bond Graph', 2011 IEEE International Symposium on ComputerAided Control System Design (CACSD), Part of 2011 IEEE Multi-Conference on Systems and Control Denver, CO, USA. September 28-30, 2011. 